\title{
Correction to: PPP with integer ambiguity resolution for GPS and Galileo using satellite products from different analysis centers
}

\author{
Marcus Glaner $^{1}\left[\right.$ Robert Weber $^{1}$
}

Published online: 9 July 2021

๑) Springer-Verlag GmbH Germany, part of Springer Nature 2021

\section{Correction to: GPS Solutions (2021) 25:102 \\ https://doi.org/10.1007/s10291-021-01140-z}

In the original version of this article, Eq. (14) was presented incorrectly. The correct equation is provided below:

$$
\overline{\mathrm{N}}_{\mathrm{IF}, \mathrm{SD}} \lambda_{\mathrm{IF}} \sim=\lambda_{1} \frac{\mathrm{f}_{1} \mathrm{f}_{2}}{\mathrm{f}_{1}^{2}-\mathrm{f}_{2}^{2}} \overline{\mathrm{WL}}_{\mathrm{SD}}+\lambda_{1} \frac{\mathrm{f}_{1}}{\mathrm{f}_{1}+\mathrm{f}_{2}}\left(\overline{\mathrm{NL}}_{\mathrm{SD}}-\mathrm{b}_{\mathrm{NL}, \mathrm{SD}}^{\mathrm{s}}\right)
$$

The original article has been corrected.

Publisher's Note Springer Nature remains neutral with regard to jurisdictional claims in published maps and institutional affiliations.

The original article can be found online at https://doi.org/10.1007/ s10291-021-01140-z.

Marcus Glaner

marcus.glaner@geo.tuwien.ac.at

1 Research Division Higher Geodesy, Department of Geodesy and Geoinformation, TU Wien, 1040 Vienna, Austria 